Portland State University

PDXScholar

\title{
Family Math Night: Increasing Engagement in University Mathematics Courses for Prospective Teachers
}

Eva Thanheiser

Portland State University, evat@pdx.edu

Follow this and additional works at: https://pdxscholar.library.pdx.edu/mth_fac

Part of the Mathematics Commons

Let us know how access to this document benefits you.

Citation Details

Thanheiser, E. (2019). Family Math Night: increasing engagement in university mathematics courses for prospective teachers. International Journal of Mathematical Education in Science and Technology, 1-29.

This Post-Print is brought to you for free and open access. It has been accepted for inclusion in Mathematics and Statistics Faculty Publications and Presentations by an authorized administrator of PDXScholar. Please contact us if we can make this document more accessible: pdxscholar@pdx.edu. 


\title{
Family Math Night: Increasing Engagement in University Mathematics Courses for Prospective
}

\author{
Teachers \\ "What is the point in taking the class if it is all about ifs instead of when?" \\ "Taking the course with Family Math Night is the only way to do it." \\ "Family Math Night brings the fun to math."
}

Eva Thanheiser

Portland State University

Prospective elementary school teachers (PSTs) often do not perceive mathematics activities as fun or engaging and perceive the mathematics tasks in their university content courses as inauthentic and irrelevant. Both these points were addressed by connecting the university classroom tasks to the $K-5$ environment via a Family Math Night (FMN). Survey results from 23 PSTs showed that PSTs were excited about the authenticity of the tasks, learned about children's mathematical thinking, and reconceptualized mathematics learning as potentially enjoyable. In combination, these results may lead to PSTs' increased engagement in the mathematics content course and, thus, result in their increased mathematics learning.

Keywords: Teacher Education; Prospective Teacher; Motivation; Belief; Family Math Night; Content Course; Mathematics

Motivating elementary school prospective teachers (PSTs) in the United States to learn mathematics in their university mathematics courses for elementary school teachers (henceforth, content course) remains a constant struggle. This challenge may stem in part from the disconnected nature of those content courses from the PSTs' interests and future careers (Kurz \& Kokic, 2011). In the United States, in contrast to most other countries, content and pedagogy are taught separately, and PSTs complete their content courses before courses focusing on pedagogy and much before being placed in schools and working with children (Ingvarson et al., 2013). However, PSTs often chose to go into teaching because they are interested in and care about children (Darling-Hammond \& Sclan, 2006; 
Philipp, 2008; Philipp et al., 2007). Thus the PSTs find themselves in a content course focussed on mathematics which is divorced from their interest (children). In this study I address this disconnect by connecting the content courses to work with children through a Family Math Night (FMN) activity.

Most colleges and universities in the United States offer mathematics content courses designed especially for PSTs. Although these courses have been part of the PST education curriculum for decades, teachers' mathematical knowledge for teaching remains a critical area in the United States (Tatto et al., 2012). For example, although PSTs (and in-service teachers) can often solve elementary mathematics problems procedurally (applying a standard algorithm), they struggle to explain the mathematics underlying the algorithms (Ball, 1988; Harkness \& Thomas, 2008; Ma, 1999; Thanheiser, 2009; Thanheiser, Browning, et al., 2014; Yang, Reys, \& Reys, 2008) or to solve the problem in a nonalgorithmic way. The PSTs experiences with mathematics "have often persuaded them that mathematics is a fixed body of rules, a dull and uninteresting subject" (Ball, 1990, p. 12) and that learning mathematics is synonymous with memorizing procedures (Graeber, 1999b). Thus, PSTs, who know how to perform the procedures, do not perceive a need to learn mathematics beyond that and do not perceive mathematics learning as enjoyable (Philippou \& Christou, 1998) or as an engaging activity (Thanheiser \& Jansen, 2016) and often either actively dislike mathematics or would avoid it if at all possible.

Philipp (2008) discussed leveraging the PSTs' interest in and care about children to motivate PSTs to learn mathematics by expanding the PSTs' circles of caring from caring about the child to include caring about the child's mathematical thinking and then about the mathematics itself. In Philipp's study, PSTs enrolled in their first content course and, at the same time, in an additional novel course about children's mathematical thinking, situating the PSTs either working directly with children 
or engaging with videos of children's mathematical thinking. Philipp and colleagues (2007) showed that both of those had positives effects on both the PSTs' content knowledge and their beliefs.

Thus, integrating mathematical content with a focus on children seems like a promising starting point for engaging PSTs in learning mathematics for teaching. Prior work has established that PSTs learn best by working with children in schools (Cady, Meier, \& Lubinski, 2006; Kurz \& Kokic, 2011). Thus, in this study, I connected the PSTs' learning in the university content course with children from the $\mathrm{K}-5$ environment by having PSTs create, develop, and enact a FMN activity at a local elementary school as part of their content course. Each student selected one of the class topics, for example, adding 2-digit numbers and then designed an activity around that that could be enacted at a local school with children grades K-5 and their parents. As such all class activities were tied to this event in some way, and thus all learning had a dual focus: first, the mathematical content and, second, the work with children. Thus, I worked at the intersection of the PSTs' interest (working with children) and the mathematical content of our course (see Figure 1).

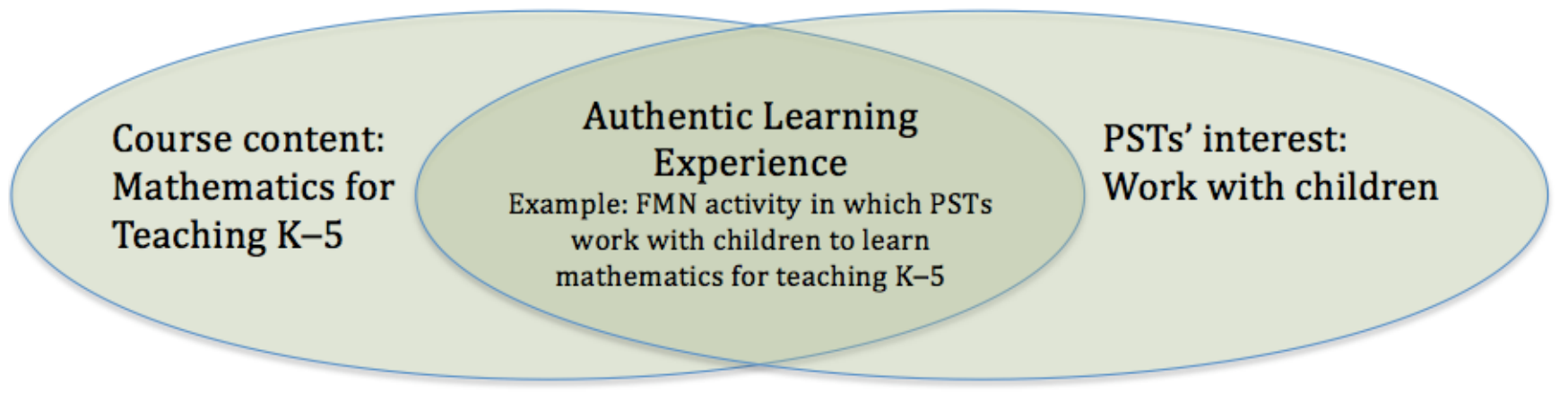

Figure 1. The Family Math Night ties together the PSTs' interest (working with children) and the course content: mathematics for teaching $\mathrm{K}-5$. 
In this study I built on prior work (Philipp, 2008; Philipp et al., 2007) and leveraged the PSTs' caring (Noddings, 1984) about and interest in working with children in a content course. This caring supports both the PSTs' learning mathematics and their reconceptualizing mathematics learning as possibly fun and engaging. However, in contrast to examining PSTs taking an additional course on children's mathematical thinking while taking their content courses, I examined a FMN activity incorporated into the mathematics content courses as a required assignment. Thus I am adding to the current literature by examining an intervention in the university mathematics content course designed to connect the mathematics to children's mathematical thinking.

I built on prior work incorporating FMNs into PST education. Traditionally experiences like a FMN in the United States have been placed and studied toward the end of the PSTs' education, in methods/pedagogy courses (i.e. Bofferding, Kastberg, \& Hoffman, 2016; Jacobbe, Ross, \& Hensberry, 2012; Kurz, 2011; Kurz \& Kokic, 2011; Lachance, 2007; Pohan \& Adams, 2007) and less typically in content courses (i.e. Freiberg, 2004). Thus, I am adding to the literature on Family Math Nights by examining the placement of a FMN as a class activity early in the PSTs' trajectories, at the beginning of their sequence of content courses for elementary school teachers, in a course focused on understanding number and operation.

I hypothesize three benefits of including a FMN activity into the content course.

1. First the activity might lead to PSTs' increased engagement in the course because the students perceive the task as authentic (Kozar \& Marcketti, 2008; Newmann, King, \& Carmichael, 2007) and interesting (Hidi \& Renninger, 2006; Middleton \& Jansen, 2011), and they thus see a need for knowing the mathematics.

2. Second, the PSTs might learn about content and about children's mathematical thinking, and thus the activity also has the potential increases the authenticity of the course. 
3. Third, PSTs might reconceptualize their view of mathematics learning as a sense making, engaging, and possibly fun/enjoyable activity.

\section{Theoretical Framework and Literature Review}

In this study I explored the implementation of a FMN as a required component of a mathematics course for elementary school teachers. In reviewing the literature, I explored the prior research on increasing engagement in such courses by focusing on tasks and task characteristics, connecting to the PSTs' interests, and PSTs' working with children. I then followed with an examination of the research on PSTs' incoming content knowledge (specifically knowledge of whole numbers), their incoming conceptualizations of mathematics learning and teaching, and their work with children or FMN activities in content courses.

\section{Increasing Engagement}

Engagement, a student's interaction with a task, can be observed in the classroom. Engagement predicts student learning (Skinner \& Pitzer, 2012) and thus is essential to learning.

Tasks and Task Characteristics to Increase Engagement. Academic tasks have been identified as "especially important determinants of motivation and engagement" (Skinner \& Pitzer, 2012, p. 28). To promote engagement, educators should provide students with tasks that are "authentic, challenging, relevant to students' experiences and concerns, hands-on, project-based, integrated across subject areas, and sufficiently open to allow students some freedom to choose their own direction and to work closely in cooperative groups over long periods of time" (Skinner \& Pitzer, 2012, p. 33).

Skinner and Pitzer further stated that tasks should be relevant and progressive as well as "intrinsically motivating, inherently interesting, and fun" (pp. 28-29). Academic tasks are often seen as meaningless, insignificant, or worthless to students' future careers (Newmann et al., 2007), that is, inauthentic. Newman and colleagues defined authentic work as "tasks that are considered meaningful, 
valuable, significant, and worthy of one's effort, in contrast to those considered nonsensical, useless, contrived, trivial, and therefore unworthy of effort" (Newman, Wehlage, \& Lamborn, 1992, p. 23). One way of making an academic task more authentic is by connecting the university classroom to the real world, to the students' future careers, or both (Newmann et al., 2007). Research has shown the importance of authentic tasks; "students who experienced higher levels of authentic instruction and assessment showed higher achievement than students who experienced lower levels of authentic instruction“" (Newmann et al., 2007, p. vii). For PSTs, we connected the university classroom to the work with children situated in a K-5 school.

\section{Increasing engagement in content courses through connecting tasks to PSTs' interest.}

Various constructs can be used to describe student participation/engagement in the classroom. Often the starting point is interest in learning; thus, we mathematics educators need to understand how interest can be first sparked and then maintained. Researchers have identified two kinds of interest: situational interest and individual interest (Hidi \& Renninger, 2006; Middleton \& Jansen, 2011).

Situational interest, on the one hand, can be seen as a spark of interest grounded in a situation that is surprising, intense, or otherwise unexpected. Situational interest is, by its nature, short lived and can thus be seen as the beginning of engagement with a task (Middleton \& Jansen, 2011). Two classes of task characteristics have been identified to contribute to situational interest: (a) degrees of novelty, intensity, or ambiguity and (b) overlap with individual interest (Middleton \& Jansen, 2011).

Situational interest can be the first motivator for a student to learn something in which he or she had no prior interest in learning and, as such, is a particularly important tool for teachers. Individual interest, on the other hand, is grounded in a person's "predisposition to reengage in particular content over time” (Hidi \& Renninger, 2006, p. 113).

In the context of this study, the PSTs' individual interest (working with children, helping children learn) was leveraged and overlapped with the mathematics content of the course. This interest 
initially sparks situational interest in learning the mathematics needed to work with the children and may lead to individual interest in learning the mathematics needed to teach.

Increasing engagement in content courses through working with children. Philipp et al. (2007) examined the effect of an early field experience on PSTs' content knowledge and beliefs and found that "those [PSTs] who studied children's mathematical thinking while learning mathematics developed more sophisticated beliefs about mathematics, teaching, and learning and improved their mathematical content knowledge more than those who did not" (p. 438). Thus working with children's thinking had positive effects on both the PSTs' content knowledge and their beliefs.

In this study, I examined how to address the PSTs' engagement in the content course through speaking to their individual interest in children and working with children by creating and enacting a Family Math Night Experience (see Benefit 1 listed above).

\section{Learning about Content and Children's Mathematical Thinking.}

Mathematical content courses for teachers have as their main curricular goals the acquisition of mathematical knowledge for teaching (MKT) (Ball, Thames, \& Phelps, 2008). MKT is defined as the knowledge needed to teach mathematics in a sense-making way with a focus on developing mathematical proficiency (Adler \& Ball, 2008; Hill, Ball, \& Schilling, 2008). MKT includes both subject-matter knowledge and pedagogical-content knowledge. Subject-matter knowledge is further divided into specialized content knowledge, common content knowledge, and horizon content knowledge. Pedagogical content knowledge is further divided into knowledge of content and students, knowledge of content and teaching, and knowledge of content and curriculum. MKT has been empirically linked to student-achievement gains (Hill, Rowan, \& Ball, 2005), and, as such, it is essential that teachers hold such knowledge. Philipp, Siegfried, and Thanheiser (in press) argue that when PSTs focus upon children's mathematical thinking while learning mathematics, then their mathematical development is qualitatively richer. In addition integrating examining children's 
mathematical thinking not only supports the development of richer mathematics but also provides a foundation for PSTs to learn how to learn from practice. At the same time integrating children's mathematical thinking makes the mathematics learning more authentic.

Therefore the goal for a mathematics content courses for PSTs, although focused on mathematics content (subject matter knowledge), also should include a focus on the other aspects of MKT, for example, children's mathematical thinking.

PSTs' incoming content knowledge of number and operation. Studies have shown that elementary school mathematics content can be difficult for PSTs to explain (Simon, 1993; Simon \& Blume, 1992; Thanheiser, Browning, et al., 2014; Thanheiser, Whitacre, \& Roy, 2014; Zazkis \& Campbell, 1996) including understanding of whole number and operation (Thanheiser, Browning, et al., 2014; Thanheiser, Whitacre, et al., 2014) . PSTs know how to proficiently execute the algorithms with whole numbers on the bases of their years of experience; however, when asked to explain why the algorithms lead to correct answers, most PSTs are not poised to do so (Ball, 1988; Ma, 1999, 2010).

A framework for PSTs' incoming conceptions of number. In prior work (Thanheiser, 2009, 2010, 2018) I developed a framework for PSTs' number conceptions when entering mathematics content courses. These conceptions were categorized into four categories, two correct (reference units and groups of ones) and two incorrect (concatenated digits plus and concatenated digits). PSTs with a reference-units conception can interpret each digit with respect to its unit type (ones, tens, hundreds). For example, in 432 they can see the 4 as 4 hundreds or 40 tens or 400 ones, the 3 as 3 tens or 30 ones, and the 2 as 2 ones. They can also relate the reference units to one another; thus they are able to see 10 ones as 1 ten, 10 tens as 1 hundred, and so forth. PSTs with a groups-of-ones conception interpret all digits with respect to the appropriate groups of ones (432 as 400 ones, 30 ones, and 2 ones) but do not interpret the digits with respect to reference units, and thus also do not relate various reference units (e.g., 10 tens to 1 hundred). PSTs with a concatenated-digits-plus conception interpret at least one digit 
with respect to an incorrect unit type at least sometimes (e.g., in 432, 4 is 400 ones but the 3 is only 3 ones). Thus, they struggle when asked to relate values of the digits to one another. PSTs with a concatenated-only conception interpret all digits with respect to ones only (e.g., 432 as 4 ones, 3 ones, and 2 ones).

PSTs' incoming conceptions. At the beginning of the content courses, generally more than $2 / 3$ of PSTs hold one of the incorrect concatenated-digits conceptions (Thanheiser, 2009, 2010, 2018). And the PSTs, who have executed the algorithms for years, are surprised by the existence of an explanation for why the algorithms lead to correct answers (Thanheiser, Philipp, Fasteen, Strand, \& Mills, 2013). The activities of the course and the FMN were designed to address the PSTs' incoming conceptions and help them develop more sophisticated conceptions of number.

In this study, I examined the PSTs' learning about content and children in a mathematics content course in which they created and enacted a Family Math Night Experience (see Benefit 2 listed above).

\section{PSTs' incoming conceptualizations of mathematics learning and teaching.}

Professional organizations such as the National Council of Teachers of Mathematics (NCTM) and the Association of Mathematics Teacher Educators (AMTE) call for reform-oriented learning and teaching, focused on sense making (National Research Council, 2001) incorporating both procedural and conceptual understanding (Hiebert \& Lefevre, 1986). In addition, teacher educators are asked to focus on such mathematical practices as making sense of problems and persevering in solving them (National Governors Association Center for Best Practices and Council of Chief State School Officers, 2010), in accordance with the Common Core State Standards (2010).

PSTs' conceptions of mathematics learning and teaching influence their perceptions and approaches to activities in their own content courses as well as guiding their actions when they become teachers (Pajares, 1992; Philipp, 2007; Thompson, 1992). PSTs enter teacher education programs with 
already formed ideas about the teaching and learning of mathematics based on their own experiences as learners (Anderson, White, \& Sullivan, 2005; Charalambous, Philippou, \& Kyriakides, 2008) and often lack experience with reform-oriented mathematics teaching themselves (Beswick, 2005; Comiti \& Ball, 1996). To teach in a way that aligns with reform mathematics, PSTs are often required to shift their beliefs about what mathematics is and how mathematics should be learned and taught (Brown, Cooney, \& Jones, 1990). Without such shifts, “teacher candidates are seen as likely to reproduce in their practice what they experienced themselves as learners'” (Ell, Hill, \& Grudnoff, 2012, pp. 55-56).

PSTs often choose to become teachers because they love children and they believe that people who love children will be effective teachers (Devine, Fahie, \& McGillicuddy, 2013). PSTs also often think that mathematics understanding is equivalent to being able to apply procedures (Graeber, 1999a) and that, thus, mathematics teachers should focus on clearly explaining and showing how to apply such procedures. This belief aligns with their own experiences in mathematics classrooms. However, although PSTs can execute (and thus apply) procedures, they often lack the conceptual understanding to explain the rationale of the procedures (Thanheiser, 2009, 2010, 2018) and may be unaware that the algorithms make sense and can be explained mathematically (Thanheiser et al., 2013). Thus PSTs are often unaware of their own lack of knowledge and so are not motivated to engage in the activities of the university mathematics content course (Pintrich, 2002).

PSTs who view mathematics as exclusively procedural and not engaging will not expect mathematics to make sense, be engaging, and possibly be fun/enjoyable for themselves in their own learning processes. In addition, PSTs with this belief lack an image of a mathematics classroom as one in which children can be sense makers - engaged and enjoying learning mathematics — and, as such, they will not have that image as a professional vision for their own classrooms. However, Francis $\mathrm{Su}$ (Su, 2019) who was the president of the Mathematical Association of America (MAA) argues that "play is intrinsically what it means to do math" and as such play and fun should be an aspect of 
mathematics learning. Thus helping PSTs develop a view of mathematical activity as sense making, engaging, and possibly fun/enjoyable is essential if we mathematics educators want the PSTs to have such visions for learning mathematics themselves and for their future classrooms.

In this study, I examined how PSTs' reconceptualized their view of mathematics learning in the context of a content course that included creating and enacting a Family Math Night Experience (see Benefit 3 listed above).

\section{Prior Work on Family Math Night Experiences}

A FMN can benefit both the PSTs and the school at which it is held. For the school, a FMN can be seen as an indicator of what good schools do to enhance the school-family partnerships (Benninga, Berkowitz, Kuehn, \& Smith, 2006; Epstein \& Salinas, 2004). Through a FMN, a school highlights mathematics in a fun environment; "the atmosphere at Family Math Night pulsates with energy— the event is something like a school carnival with mathematics as its theme" (Lachance, 2007, p. 406)!

FMNs can build connections between coursework and classrooms, provide interactions with children, and help PSTs gain experiences working with families (Bofferding et al., 2016). Through FMNs, PSTs can try out what they have learned in their own classrooms (Kurz, 2011). The PSTs can take some of the mathematics tasks they discussed in the university classroom and see how children (either individual or small groups) work through them. As such, a FMN provides a hands-on version of the more theoretical learning in the university classroom. In this study, I purposefully incorporated a FMN into a content course early in the PSTs' careers to increase engagement in that course (and possibly following courses), to bridge the disconnection between the university course and the $\mathrm{K}-5$ setting, and especially to engage the PSTs in working with children. PSTs typically enjoy being involved in FMN activities (Freiberg, 2004) in the context of their university courses. 
Some researchers have examined the effects, benefits, or opportunities provided by incorporating a FMN into a mathematics methods course. Jacobbe and colleagues (2012), for example, examined the PSTs' perceptions of parental involvement for low-income families and found that being part of a FMN increased PSTs' perceptions of parental involvement. Bofferding et al. (2016) studied the opportunities to improve PSTs' understanding of parents' roles and expectations through a FMN and found that the event helped PSTs feel more comfortable working with parents.

Other studies have been focused on PSTs' learning about how children think about or learn mathematics (i.e. Kurz \& Kokic, 2011). Kurz and Kokic identified four themes in PSTs' reflections about FMN. These themes indicated that PSTs thought about the need for “(1) activity adjustment, (2) engagement through guiding and questioning, (3) motivational issues, and (4) the use of manipulatives and visuals" (p. 24) to guide children's learning in mathematics.

Typical structures for FMN assignments may include an activity description (with modifications based on feedback and implementation), accompanying questions and modification ideas, and reflections (Kurz, 2011; Lachance, 2007). In some cases all materials are collected into a portfolio (Lachance, 2007).

In this study, PSTs created and subsequently enacted a FMN activity at a local elementary school as part of their mathematics content course for PSTs. The FMN is an integral part of the course (a more thorough description follows). I sought to answer the following research questions:

1) How do PSTs perceive the inclusion of a FMN project into a content course?

2) What do PSTs learn about content and children through the inclusion of a FMN project into a content course (addressing curricular goals)?

3) How does the inclusion of a FMN project into a content course affect the PSTs' conceptualizations of mathematics learning and teaching? 


\section{Methods}

In this section I describe the participants and the setting, the Family Math Night activity, and the data-collection and data-analysis procedures.

\section{Participants and Setting}

The participants in the study were 23 PSTs in an 11-week mathematics content course for PSTs at a large, state university in the Northwestern United States. The participants were 4 males and 19 females, a typical ratio for this course. The content course is the first in a sequence of three required mathematics content courses that are prerequisites for PSTs entering the Graduate School of Education. PSTs in this program earn a Bachelors degree and then enter the Graduate School of Education to earn a Masters of Education degree and an initial teaching licence. Mathematics methods (pedagogy) courses are included in the Graduate School of Education program. The content courses are taught through the mathematics department and are taught by mathematics educators and teaching assistants. The courses are designed to help PSTs make sense of the mathematics they will teach as elementary school teachers. The course in this study was focused on number and operation and met twice weekly for 110 minutes per meeting. As part of their regular content course, all PSTs created and enacted a FMN activity (described in the next section) designed to link the class activities to the $\mathrm{K}-5$ setting.

\section{Family Math Night Class Activities}

The PSTs were informed of the FMN activity on the first day of the class in their content course. The setting of the FMN would be carnival like, the children would move from booth to booth engaging in various activities. Each activity was supposed to be 15-20 minutes in length, interactive, 
teach some mathematics, and be fun and engaging. The goal was to engage children from $\mathrm{K}-5$, and as such the activity had to have different entry points.

The instructor explained the process over the first few weeks. In each class session during Weeks 1-3, all class activities were discussed in terms of a FMN. This allowed the instructor to motivate the PSTs to actively engage in deeply examining the activities of the course. The PSTs were willing to engage since they may be in charge of putting on the activities for children later at the FMN. For example, after working on the odd-plus-odd task (see Figure 2) and examining what all is essential to mathematically justify such a statement, PSTs considered how they would pose such a question in a K-5 classroom context in general and in the FMN context in particular, how they would adjust the question for various levels, how they would adjust the goals for various levels. This opened up discussions about what it means to be odd and even, what it means to add, what it means to talk about general cases, etc. While the PSTs were able to convince themselves of the answer easily (most often by trying out a few numbers), they had a hard time seeing what is needed for a justification of all cases. However, when put in the context of thinking about working with children the PSTs were able to dissect the problem considering different levels of prior knowledge from students, etc. Consider how to push for the general case with children required the PSTs to think through that themselves.

For each problem the class tackled, PSTs discussed how to develop follow-up activities to adjust the task to various levels. This again allowed the PSTs to engage in a deeper level. If a child, for example, already knew something, how could they push the boundaries of that knowledge. Adjusting a task so that is a low floor and a high ceiling (Boaler, 2014) and being able to adjust in various directions requires a deep mathematical understanding of the content. Asking PSTs to think about this requires them to reconsider what mathematical understanding is needed to teach. While the PSTs perceived these activities as preparation of the FMN activity with children, the activities were also an 
essential part of examining the mathematics content of each task and as such were part of the content course as is.

\title{
Question
}

\author{
When you add an odd number to another odd \\ number, will your result be \\ (a) always even, \\ (b) always odd, \\ (c) sometimes odd and sometimes even (depending \\ on the numbers?
}

Answer the question and justify your thinking.

When answering the question above, please justify at the level of 3 rd -5 th graders (i.e., use language you think they would understand).

Figure 2. Prompt for Odd + Odd task.

In preparation for the actual event, the class viewed images from prior FMN activities working with various problems (included the one in Figure 2) to have an image of what a FMN could look like.

During Week 4, pairs of PSTs chose and signed up for a topic such as: problem solving, justification, addition/subtraction (with manipulatives), addition/subtraction (alternative algorithms), number systems (Egyptian, Mayan), multiplication, division, number-theory topics, and so on. The topics reflected the curriculum of the class. Two pairs of PSTs signed up for the same topic but then coordinated different approaches to it. PSTs were asked to create or find/modify/develop a mathematical activity for their topic and think through how they would enact it with elementary school students. They were welcome to use the activities from our course or go beyond those. In particular, as class assignments, PSTs were asked to (a) explore the grade-level expectations for their topics within the Common Core State Standards (2010), (b) explicate a mathematical goal of their activity, (c) find ideas for their topics using various resources such as, but not limited to, the publication Teaching Children Mathematics, www.illuminations.org, and the NCTM website www.nctm.org, (d) find ideas 
in their textbooks and notes from class, and, finally (e) explore the general internet for ideas. While the mathematical focus of the various groups was different depending on the activities they signed up for all PSTs grappled with the idea that each activity should have a mathematical goal. Identifying a clear mathematical goal is an essential skill for a teacher and the level of understanding the mathematics related to a goal determines the way a teacher is able to teach. Understanding the mathematics is required to be able to explicate a mathematical goal.

During Week 6, each pair of PSTs submitted a first idea. During Week 7, the pairs of PSTs received feedback on their ideas in a one-on-one meeting with the instructor of the course. The purposes for these meetings were to identify a clear mathematical goal for each activity and ensure that the activity was designed/modified with that goal in mind. This was yet another opportunity for the PSTs to work with the instructor to learn more about the specific mathematical idea they were working on. After receiving this feedback, the pairs of PSTs created a full version of the activity, which they then shared during class (Week 8). During this session half the PSTs presented their activities, in pairs, and the other half engaged with the activities; then the roles were reversed. This session afforded each PST pair the opportunity to (a) try out their own activity and receive feedback from both their peers and the instructor and to (b) engage with other PSTs' activities and give feedback. This session also allowed all PSTs to (re)engage in the mathematical content explored throughout the course. They engaged in activities, critiqued the goals and the activities, and as such reviewed all the content again. After this session, the PSTs again revised their activity on the basis of the feedback from their classmates and then enacted the activity at a local neighbourhood school that volunteered to host the family math night (at the end of Week 8).

Parents and other guests were invited to attend the FMN and engage in the activities with their children; the PSTs gave them handouts that included a description of the activity as well as follow-up 
activities for use at home with their child/children. Activities were designed for the $\mathrm{K}-5$ range with foci differing by grade band. In Week 11 each pair submitted a portfolio and presented a brief presentation on the experience to their classmates. My goals for portfolio and presentation were for each pair of PSTs to reflect on their activity, the mathematics of their activity, as well as on the children's responses to deepen their understanding. A further goal for the presentations was for all PSTs to reflect on all tasks together during the final class session.

As such the FMN activity provided an opportunity for each PSTs to explore one of the mathematics topics of the class in depth and go beyond what is possible in a regular content course with respect to that topic. For example, one pair of PSTs focused on multiple representations/solution strategies for multiplication of single and double digit numbers. They prepared two boards and two sets of cards and asked students to sort cards with the various representations and solution strategies onto the board (see Figure 3). Thus, they delved more deeply into the meaning of multiplication, its various representations, the connection between those representations, etc. This activity promoted discussions of these representations and solution strategies and comparisons among them.
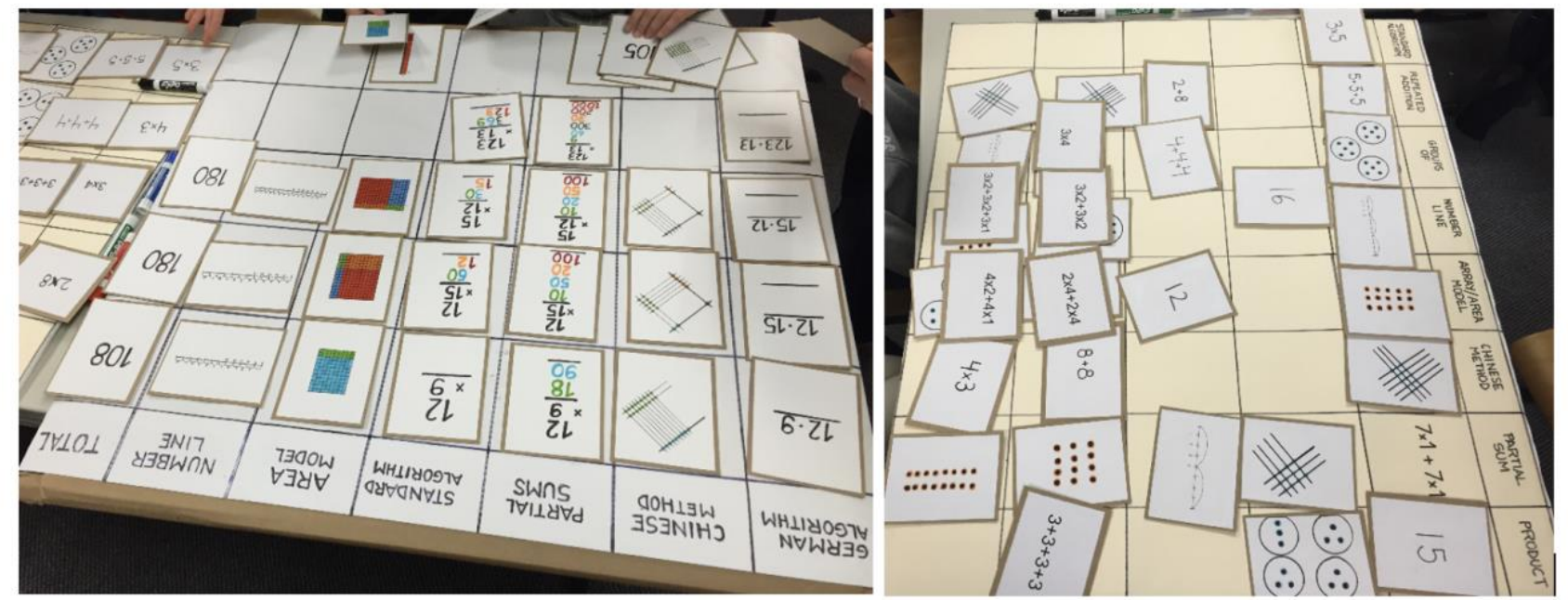
Figure 3. Sample FMN activity with focus on recognizing, sorting, and learning about various representations and solution strategies for multiplication.

Other activities included problem solving activities such as given a number of heads and feed to calculate how many two- and four-legged animals were present. The goal for these problems was to establish and focus on various problem solving strategies such as drawing, acting out, etc. (see Figure 4). The problem difficulty was changed by changing the number of heads and feet and then by asking students to generalize beyond a specific case.

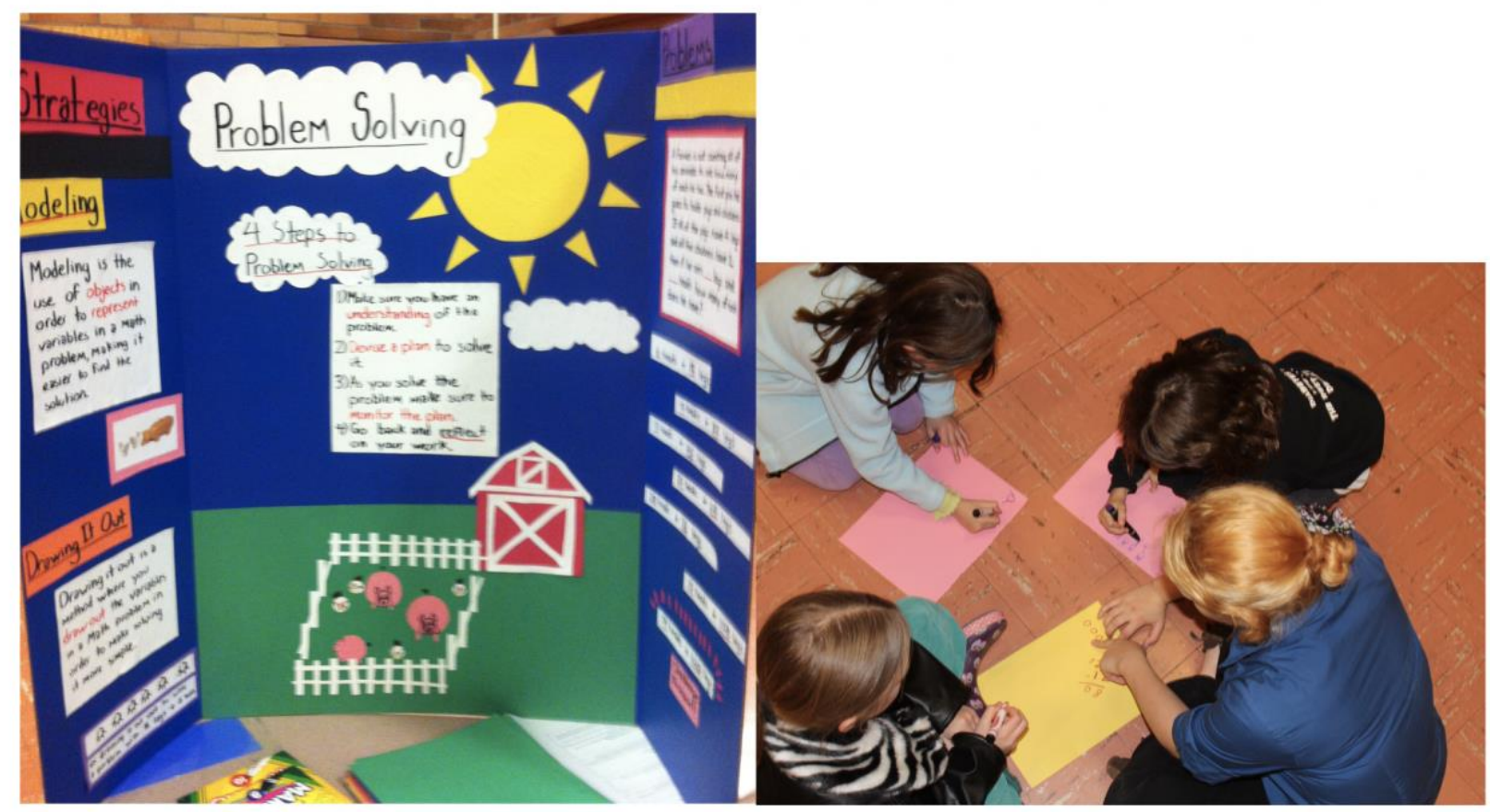

Figure 4. Sample FMN activity with focus on problem solving.

One of the addition and subtraction activities included shopping from a catalogue of items with a given budget and a purpose. Multiplication and division activities included making sense of various ways to multiply such as the lattice method works and hopping along a number line to establish that $\mathrm{x}$ number of hops of y size is equivalent in distance to y number of hops of x size (see Figure 5). 

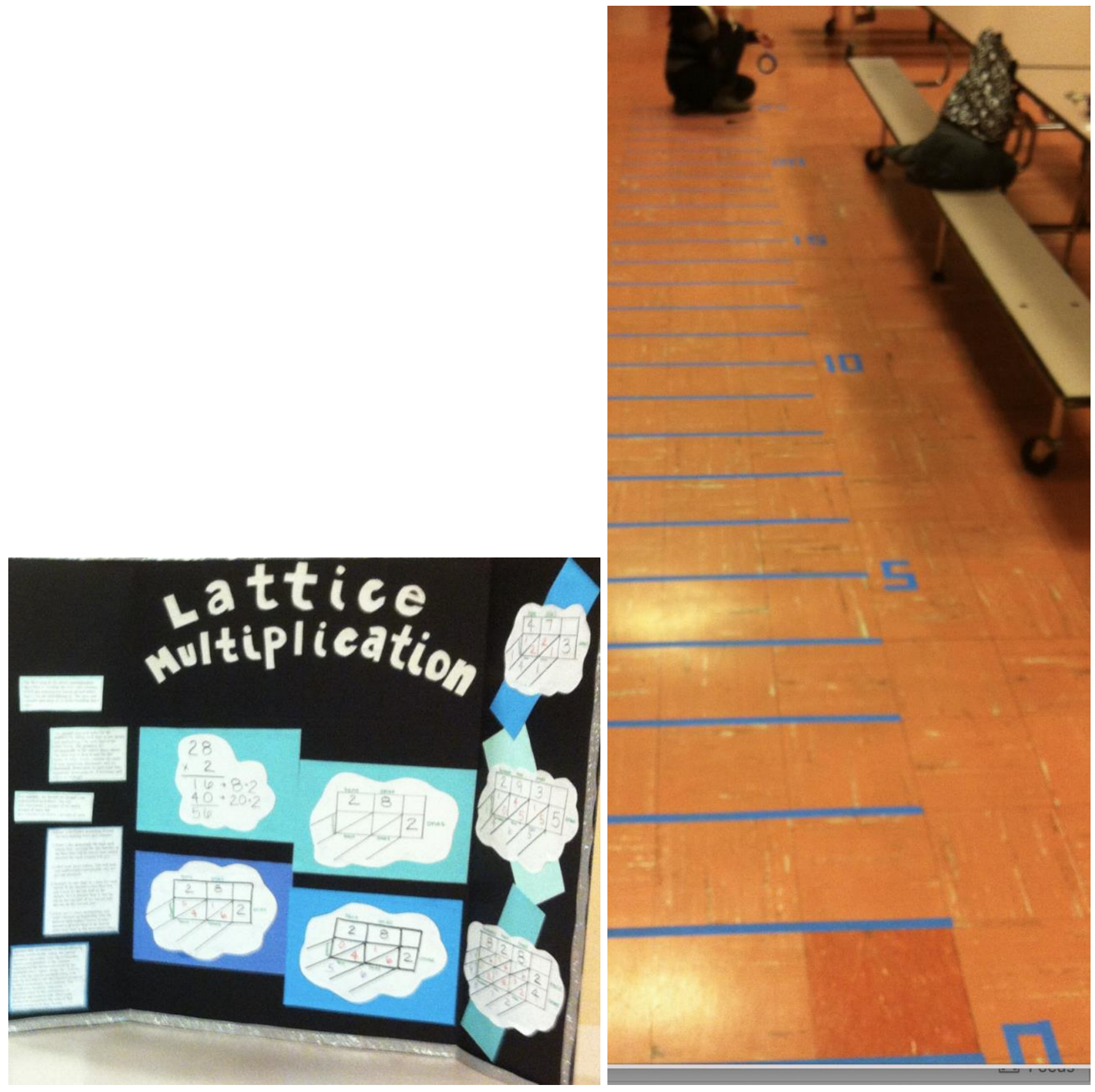

Figure 5. Sample FMN activities focusing on lattice multiplication and multiplication as equidistant hops.

Other activities utilized historical number system such as the Egyptian and Mayan number systems to explore aspects of our base ten system (Thanheiser \& Melhuish, 2018) (see Figure 6) 


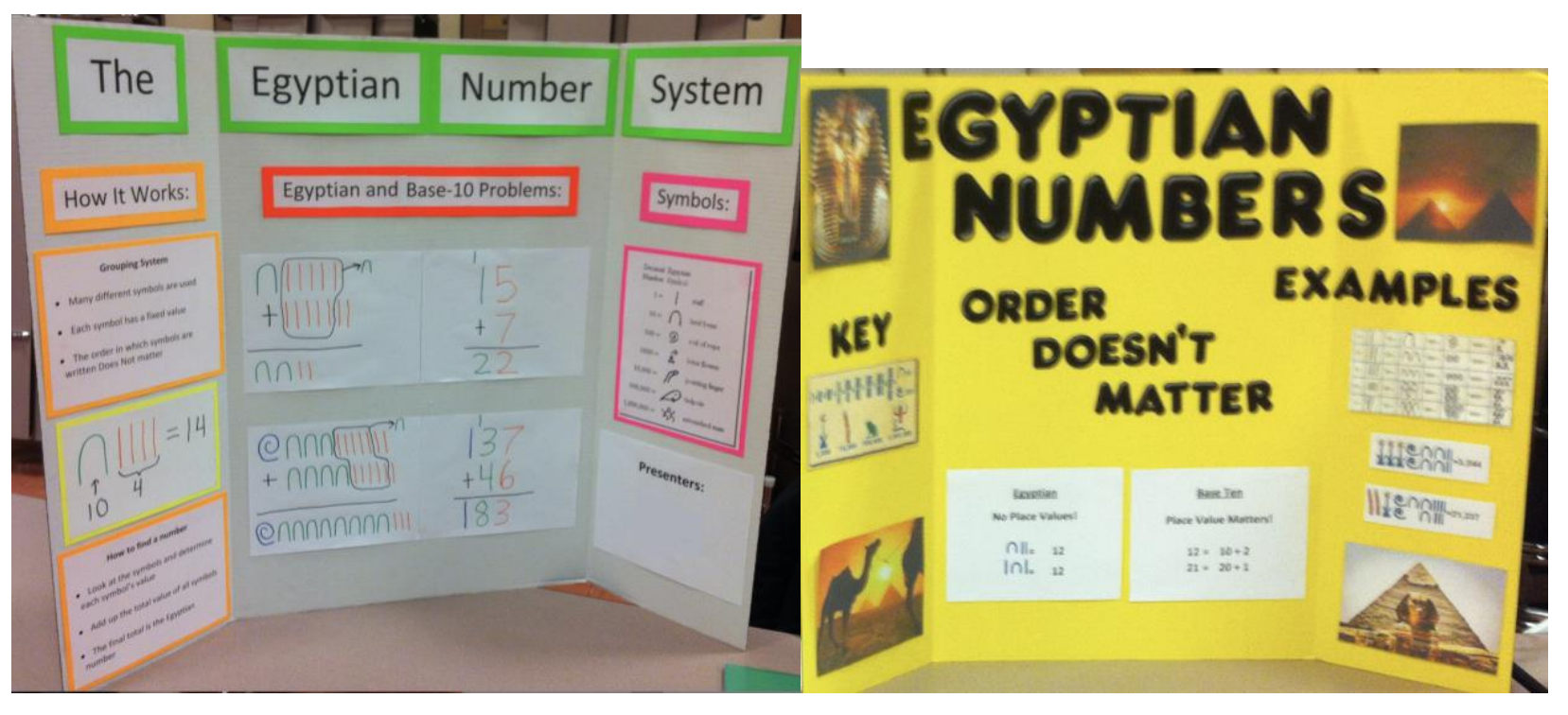

Figure 6. Sample FMN activity with focus on place value via exploring the Egyptian Number System.

I structured the FMN activity so that the PSTs would more deeply engage with one mathematical topic of the course in addition to their engagement with all other topics. Another purpose for the FMN activity was to connect all class activities to the $\mathrm{K}-5$ setting and thereby motivate the PSTs to learn because the learning was tied to their future careers. We discussed the following questions for all course activities thus tying back to the mathematical focus:

1. What mathematics do we need to know to help children learn?

2. What mathematics do we need to know to help children tackle a topic or problem?

3. What mathematical understanding do we need to understand children's solutions (common and uncommon)?

4. How can we accurately represent the mathematical idea?

5. How can we provide mathematical explanations for common rules?

\section{Data Collection}


Twenty-three PSTs responded to 3 online surveys about their experience with the FMN activity throughout the term. In completing these surveys, the PSTs reflected on their experiences with respect to the FMN. PSTs completed Survey 1 after choosing a topic and developing initial ideas about their project (Week 6), Survey 2 immediately after the FMN (Week 8), and Survey 3 at the end of the course (Week 11). The surveys were focused on PSTs' perceptions about the inclusion of a FMN into the course. For example, they were asked how they felt about creating and enacting a FMN activity and how they thought such an activity contributed to their learning in the class. In Surveys 1 and 3, PSTs reacted to incorporation of a FMN activity into the content course: reflecting in Survey 1 about the FMN before enacting it and in Survey 3 at the end of the course. Survey 2 was focused on the PSTs' immediate reactions after executing the FMN activity. As such, Survey 2 questions differed from those in Surveys 1 and 3. Results will be reported either with respect to a specific survey (i.e. before the enactment of the FMN) or with respect to all three surveys (i.e. this theme was mentioned in at least one of the three surveys). A comparison of themes by surveys is not possible as the questions were open and differed from survey to survey. Cross-survey results provide less information than the themes that surfaced for various PSTs. A full list of survey questions is attached in the Appendix.

\section{Data Analysis}

Because PSTs' reactions to a FMN activity in the context of a content course have not been researched extensively, I used a thematic approach (Braun \& Clarke, 2006), "identifying, analyzing and reporting patterns (themes)" (Braun \& Clarke, 2006, p. 82) to analyze the survey data. A colleague and I followed Braun and Clarke's process by first familiarizing ourselves with the survey data. I (as the instructor) read the survey responses as soon as they came in (during the term), and then both of us read through all responses after the term ended and began data analysis. We read through all responses to each question several times and then began initial generation of codes. We independently identified 
various codes for each survey question then met to compare the codes and decide which codes were most appropriate for each question. We next began to look for overarching themes across various codes, first creating a list themes, subthemes, and individual codes. This process eventually led to a coding scheme and an initial naming for all themes/codes. After the coding scheme was set, we recoded all the data according to the scheme. We met to discuss all codes and resolved disagreements through discussion to reach a final coding scheme and a final set of agreed upon coded survey responses. In the next paragraph are example responses and our coding of those responses.

Question 8 on Survey 1, completed before the FMN event, was "How do you think the Family Math Night Activity contributes to your learning in this class?" PST responses included "It is a handson activity that I will be doing when I am a teacher" [Alex,1 S1], "We get to take what we have learned in class and actually get to apply it" [Katie, S1], and "[It is] hands on experience working with children and an actual application of everything that we have been reading about and discussing" [Melodie, S1]. In initially reading the survey responses to this question, we noted the PSTs' referring to (a) hands-on experience, (b) putting what they have learned into practice, (c) applying what they have learned, and (d) working first hand with students. Thus, those ideas were established as codes. We decided to combine the last code "working first hand with students" with the prior three, because it is an instantiation of "hands-on experience for a future teacher" to form a theme: authenticity of the task. This theme seemed to capture these codes because the PSTs seemed to consider these tasks as meaningful (Newmann et al., 2007) hands-on, and relevant to their experiences and concerns (Skinner \& Pitzer, 2012).

After we identified a final theme (collection of codes) and coded all the data, a frequency count was established for each code, for each occurrence across all questions and across all three surveys.

1 All names are pseudonyms. 
Some codes appear more naturally on one or two of the three surveys because of the nature of the questions (see appendix). Because the questions varied across surveys, I do not note increases or decreases of themes across surveys, but I do report the occurrence of themes in each survey.

To determine the PSTs' conceptions of number at the beginning and end of the term, I used Author's framework (Thanheiser, 2009, 2010) to code the PSTs' conceptions as correct (referenceunits or groups-of-ones) or incorrect (concatenated-digits-plus or concatenated-digits-only) at the beginning and the end of the term. All data were double coded by a second researcher, with an interrater reliability of $82 \%$ for the beginning of the term and $91 \%$ for the end of the term. All disagreements were resolved through discussion.

\section{Results}

In this section I discuss the themes that emerged from the survey-data analysis addressing the research questions listed above; I list them here and follow with a detailed discussion of each theme.

1. How do PSTs perceive the inclusion of a FMN project into a content course? PSTs reported that they were excited about the authenticity of the FMN activity. They considered the FMN activity meaningful (Newmann et al., 2007), hands-on, and relevant to their experiences and concerns (Skinner \& Pitzer, 2012).

2. What do PSTs learn about content and children through the inclusion of a FMN project into a content course (addressing curricular goals)? I begin this section with a review of the development of the PSTs' conceptions of number. I follow with their report on the FMN. PSTs reported that they learned MKT through the FMN. PSTs also reported that they were surprised by the facts that (a) children were not only engaged in the activities but also seemed to enjoy them and (b) that children come to school with different levels of prior knowledge and use various methods to solve problems. 
3. How does the inclusion of a FMN project into a content course affect the PSTs' conceptualizations of mathematics learning and teaching? . PSTs reported that the FMN was a great learning experience and that they had a lot of fun.

I close this section with the PSTs' recommendation as to whether to enroll in a class with or without FMN.

\section{How do PSTs perceive the inclusion of a FMN project into a content course?}

PSTs reported that they were excited about the authentic task. The PSTs reported that they were excited about the authenticity of the FMN activity. All 23 PSTs in the study expressed excitement about the fact that the FMN activity is/was an authentic activity (see Table

1 for the authenticity themes). Twenty-one PSTs explicitly focussed on the enactment part of the FMN activity. Rather than just planning a task in class and submitting a plan for evaluation, they would/did also enact the task at a local school with elementary-school-aged children. Dena, for example, stated, "[FMN] makes us apply all that we have learned. We have been figuring out how to teach, but this is actually a chance for us to do it." [Dena, S1]. This theme ties in directly with being motivated to attend to and engage with the class activities, because the PSTs will use what they learned in class during FMN. Thus it has the potential to increase engagement in the math activities of the course.

Seventeen PSTs specifically mentioned being excited to be working with real children. Jennifer, for example, explained

Family Math Night is hands-on. Everything that we have learned about explanations and justification and talking about math are all things I can apply to this night. Reading about it and talking about it is only doing so much for my brain. Actually putting it to real practice with real children ... is going to be extremely beneficial to my learning experience. Getting to watch it all play out will help me more. [Jennifer, S1] 
Hannah also focused on working with real students; she stated, "FMN will give us a chance to watch real students doing math. We can read about it and discuss it all we want, but there's nothing like actually watching a student work through a problem" [Hannah, S1]. Thus, before the enactment of FMN the PSTs were excited to be able to apply what they had learned in class to work with real children.

Immediately following the FMN, the PSTs shared the same sentiment. Cassie, for example, stated, "It was great taking what we have been learning in class and using it in a real-life situation" [Cassie, S2]. According to Heather, "Putting what we've learned to use and actually having the opportunity to spend time with students is SO beneficial, rather than learning everything hypothetically in class" [Heather, S2]. Heather shared a similar sentiment at the end of class: "[FMN] affected my experience because I was able to interact with students instead of sit in the classroom and imagine how a child would do my activity" [Heather, S3].

Thus PSTs were excited about the authenticity of the FMN at the beginning of the term (S1) and all PSTs mentioned this theme at least once over the three surveys. Table 1 displays the occurrence of the themes in Survey 1 as well as mentioned at least once through all three surveys. Some PSTs explicated how this excitement translated into motivation and engagement for them. Hannah, for example, stated, "I think it [FMN activity] kept us engaged throughout the term because we knew that we'd be applying what we had learned" [Hannah, S3]. The PSTs' impetus for engagement was the fact that they knew that they would put their learning into practice.

Table 1. Authenticity Themes From Surveys (Numbers of PSTs)

\begin{tabular}{|c|c|c|}
\hline Themes & $\begin{array}{c}\mathrm{S} 1 \\
(n=23)\end{array}$ & $\begin{array}{l}\mathrm{S} 1 \text { or } \mathrm{S} 2 \text { or } \mathrm{S} 3 \\
\quad(n=23)\end{array}$ \\
\hline $\begin{array}{l}\text { PSTs reported that they were excited about the } \\
\text { authentic task. }\end{array}$ & $21(91 \%)$ & $\begin{array}{c}23 \\
(100 \%)\end{array}$ \\
\hline $\begin{array}{l}\text { PSTs reported that they were excited about putting } \\
\text { what they learned into practice. }\end{array}$ & $\begin{array}{c}19 \\
(82 \%)\end{array}$ & $\begin{array}{c}21 \\
(91 \%)\end{array}$ \\
\hline
\end{tabular}


PSTs reported they were excited to work with realtheme in either survey is 23.

\section{The PSTs stated that they were excited about and confident in their abilities to create a}

FMN activity. Before the FMN activity PSTs expressed excitement about and confidence their abilities to create FMN activities. Fourteen PSTs explicitly mentioned being excited (see Table 2); Nina, for example, stated, "I'm excited. I can't wait to interact with the children" [Nina, S1], and Katie stated, "I am pretty excited to take what I have learned in this class and be able to apply it to real life, and work with children" [Katie, S1]. In addition, 14 of the PSTs explicitly expressed their confidence in their abilities to create a FMN. For example, Annette stated, "I feel pretty confident in this project" [Annette, S1]. Eight PSTs, however, expressed some hesitation about planning their FMN activities; most of these hesitant PSTs had signed up for topics that were covered later in the course, were more complex, or both. Reba, for example, stated, "I think the fact that my topic is multiplication, one we have just started to delve into in class, may be part of the reason I felt unsure when starting to plan the activity" [Reba, S1].

Table 2. Confidence/Hesitation Themes From Surveys (Numbers of PSTs)

\begin{tabular}{lcc}
\hline \multicolumn{1}{c}{ Themes } & $\begin{array}{c}\mathrm{S} 1 \\
(n=23)\end{array}$ & $\begin{array}{c}\mathrm{S} 1 \text { or S2 or S3 } \\
(n=23)\end{array}$ \\
\hline The PSTs reported that they were excited. & 14 & 14 \\
& $(61 \%)$ & 14 \\
& & $(61 \%)$ \\
The PSTs reported they were confident in their & 14 & 8 \\
abilities to create an activity. & $(61 \%)$ & $(35 \%)$ \\
$\begin{array}{l}\text { Some PSTs reported hesitation (mostly due to later } \\
\text { placement of topic). }\end{array}$ & $(35 \%)$ & \\
\end{tabular}


The PSTs reported that the FMN activities went well. After the FMN activity, 21 of 23 PSTs stated that their group's FMN activity went well. Cassie, for example, stated, "It went great! Right from the start we had a table full of children, and it stayed like that the entire time. I couldn't believe how fast an hour and a half went" [Cassie, S2], and Jessica stated, "It went really, really well! We had such a great time, and [my partner] and I were surprised at how excited the kids got while working on our worksheet!" [Jessica, S2].

Only two PSTs did not explicitly mention that the activity went well; Sarah and Reba stated that they thought they were prepared but they were not. "I thought I was at least prepared for what was going to happen, but I was not" [Sarah, S2]. They had not prepared for the various levels of understanding. Sarah explained, "Every student had a different level of understanding with division and multiplication" [Sarah, S2]. Thus, although Sarah and Reba did not feel adequately prepared, they still learned about the children's varying levels of readiness.

Table 3. Success of FMN Activity (Numbers of PSTs)

\begin{tabular}{ccc}
\hline Themes & $\begin{array}{c}\mathrm{S} 2 \\
(n=23)\end{array}$ & $\begin{array}{c}\text { S1 or S2 or S3 } \\
(n=23)\end{array}$ \\
\hline The PSTs reported that the FMN went well. & 21 & 21 \\
$(91 \%)$ & $(91 \%)$ \\
\hline
\end{tabular}

Of the 21 PSTs who stated that the FMN went well, 16 PSTs explicitly stated that the activity was a lot of fun, a great learning experience, or both (more on this below in Category 3). Riccie, for example, stated, "I think it went really well. I had a lot of fun. Working with the kids was great" [Riccie, S2].

The fact that PSTs reported that the FMN activity went well validated the work they put into the course and the preparation for family math night. Jessica was enthusiastic about her learning: 
I learned a lot! It was great to be able to put everything we learned over the term together. I learned some great ways to get a discussion going. Also, I learned that giving a child as long as they need to look at a problem is totally fine. They are usually able to figure it out; it may just take some kids longer than others. Really was amazing to be able to watch these kids learn and have them teach me at the same time! [Jessica, S2]

Jason explained the benefits of the FMN activity:

The [FMN was a] valuable experience of creating and enacting a lesson plan for grade school students. It also allowed me to study certain mathematical concepts further and gain a better understanding of both Base-ten and the Egyptian number system. I can now take what I have learned from this activity and use it to create lessons that will clearly explain certain fundamental mathematical concepts. [Jason, S3]

Reba stated, "[My] learning in this class was very focused and determined because I knew that I would need to know the subject well enough to teach it, and that is a whole different level of understanding for me [Reba, S3], and Ron stated that the FMN activity "really tied everything we learned in class together" [Ron, S3]. Richard added that the FMN activity "made me want to better understand the concepts in class so that I can teach them'[Richard, S3].

\section{What do PSTs learn about content and children through the inclusion of a FMN project into a content course (addressing curricular goals)?}

PSTs' Mathematics Learning Through the FMN. The general excitement about the FMN activity served as an impetus to the PSTs for learning, in general, and learning MKT, in particular. Eighteen of the 23 PTs stated that they learned mathematics as a result of planning and enacting their FMN activity (see Table 7). Katie, for example, stated, "I have learned a lot more about mathematics and why certain steps that we take work" [Katie, S3]. And Jason explained, "Preparing for this activity helped to reinforce what we had already learned in this course about place value and what is really happening when we regroup and borrow in addition and subtraction" [Jason, S2]. Comments such as these illuminate that the FMN can help PSTs develop better understanding of the mathematics discussed in the course; Jason explicitly mentioned the preparation for the activity as an impetus for his learning. 
Table 7. FMN Activity's Effect on Mathematics Learning (Numbers of PSTs)

\begin{tabular}{lcc}
\hline \multicolumn{1}{c}{ Themes } & $\begin{array}{c}\mathrm{S} 3 \\
(n=23)\end{array}$ & $\begin{array}{c}\mathrm{S} 1 \text { or S2 or S3 } \\
(n=23)\end{array}$ \\
\hline $\begin{array}{l}\text { The PSTs reported that the FMN activity resulted } \\
\text { in their learning mathematics. }\end{array}$ & $\begin{array}{c}18 \\
(78 \%)\end{array}$ & $\begin{array}{c}18 \\
(78 \%)\end{array}$ \\
\hline
\end{tabular}

The main goal and initial impetus of the FMN activity was to motivate PSTs to deepen their MKT. Thus, the fact that most PSTs felt that they learned mathematics through this activity is important inasmuch as PSTs were able to recognize and value their own learning.

The development of the PSTs' conceptions of number. When entering their first mathematics content course, most PSTs do not hold correct conceptions of number (Thanheiser, 2009, 2010, 2018). The same held true in this study. At the beginning of the course, only 5 of the 23 PSTs held a correct conception of number that enabled them to explain the mathematics underlying regrouping within the context of addition and subtraction (see Table 8). This finding is consistent with prior findings (Thanheiser, 2009, 2010, 2018). PSTs struggled to explain regrouping and the meaning of the regrouped digits in the addition and subtraction algorithms.

Table 8. PSTs Pre and Post Number Conceptions (Numbers of PSTs)

PSTs Conceptions

$(n=23)$

Correct Conception Incorrect conception

\begin{tabular}{ccc}
\hline At the beginning of the course & 5 & 18 \\
& $(22 \%)$ & $(78 \%)$ \\
At the end of the course & 21 & 2 \\
& $(91 \%)$ & $(9 \%)$ \\
\hline
\end{tabular}

I share results from Jessica, who gave typical explanations in the pre- and post-assessments. Preassessment responses come from a preinterview conducted with all PSTs; postassessment responses 
are from a survey all PSTs completed at the end of the course. Jessica initially described all the regrouped digits in $527-135$ and in $389+475$ (see Figure 4 and Table 9) as tens.
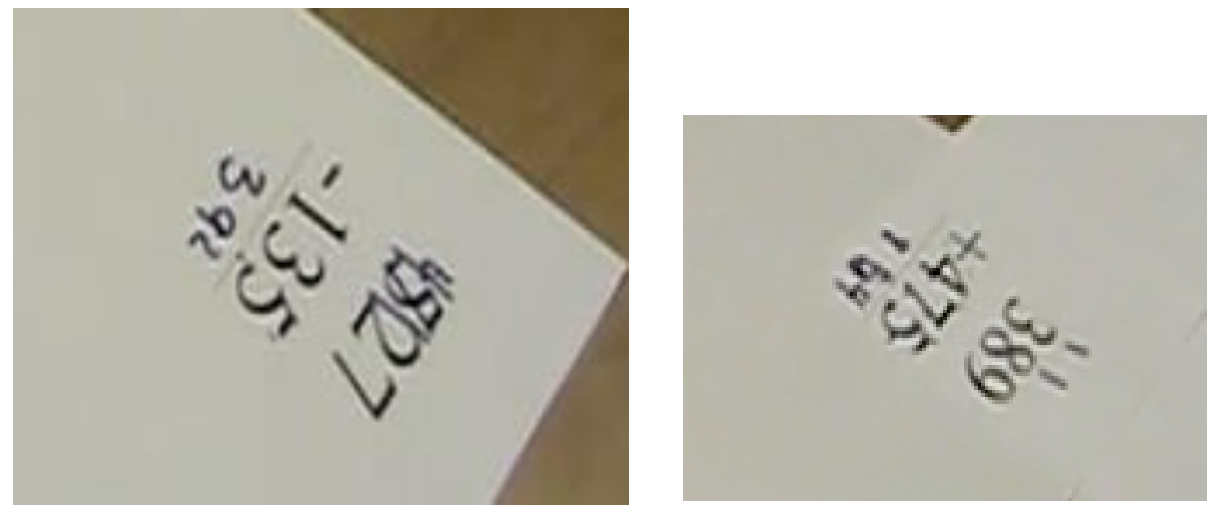

Figure 4. Jessica's preassessment responses.

Table 9. Jessica's preassessment responses

Jessica explained the subtraction:

She explained the regrouping as follows:

Jessica explained the mathematics underlying the algorithm:

In the addition problem, Jessica counted up again to arrive at 14 in the ones' column and 16 in the tens' column. She explained further:
I just started [in the ones' column ...]; 7, 6, 5, 4, 3, 2 [counts backward and points to the 2] ...; [moves to the tens' column] I have 12, 'cause I took away from the 5 [in the hundreds' column], made it 4 , made this [ 2 in the tens' column] 12; [counts back from 12] 12, 11, 10, 9 [points to the 9]; 4 minus 1, 3 [points to the 3].

Two minus 3 would make a negative number, so I need to move a 10 over; so this [regrouped number in tens' column] would be 12 , so it [the answer to subtraction in the tens' column] would be a positive number. So I crossed out the 5 , making it a 4 , moving the 10 over to the 2 , making that 12 .

When you have a number that is smaller on top ...,you need to cross out the number [in the next place over] - in this case it is a 5 - to make that one number less, which would be 4 , and move your 10 over to the spot, so you have 12. [She goes on to explain ...] basically the 1 was just put there so you can minus your $12-2$, because if you minus $2-3$ you would get a negative number, and we cannot have a negative in here because that would not make any sense.

This [first regrouped digit] is a 10 that was left over from the total in the ones' column, $9+5=14$; we took the 4 and wrote it down, carried the 1 over to the tens' column. We added the $8+$ 1 , which is $9 ; 9+7=16$, wrote the 6 down, carried the tens' column again, moved it over to the top, and then just added those numbers up and got 8 . 
Jessica referred to the regrouped 1 in the hundreds' column as a "ten that we moved up to the top that we added with the numbers in the hundreds' column." Jessica saw each of the two regrouped 1s as 10s, one from the 14 ones and one from the 16 in the tens' column.

Throughout the course, most PSTs developed increasingly sophisticated conceptions of number so that by the end of the course 21 of 23 PSTs held a correct conception of number (see Table 8).

Jessica, for example, was at the end able to explain regrouping and the meaning of the regrouped digits appropriately (see Figures 5 and 6).

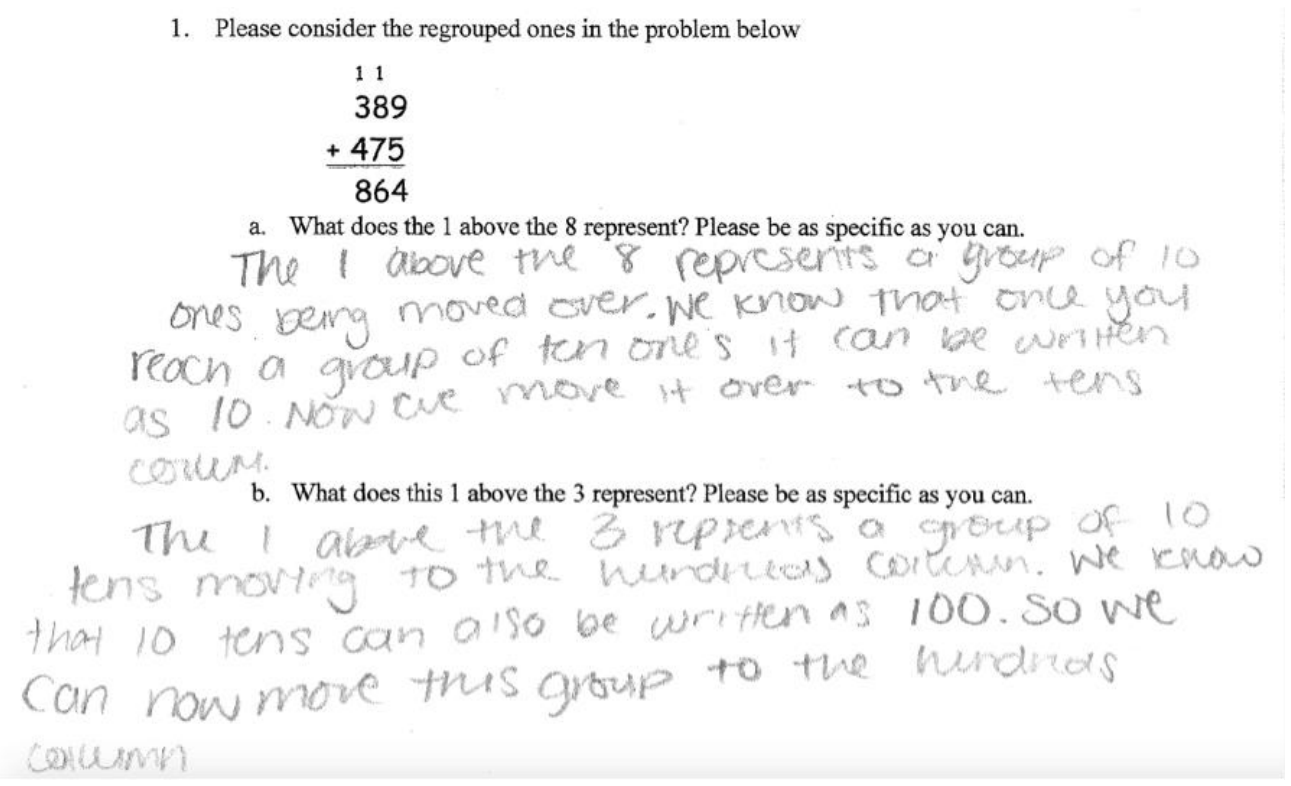

Figure 5. Jessica's post response to the addition question. 


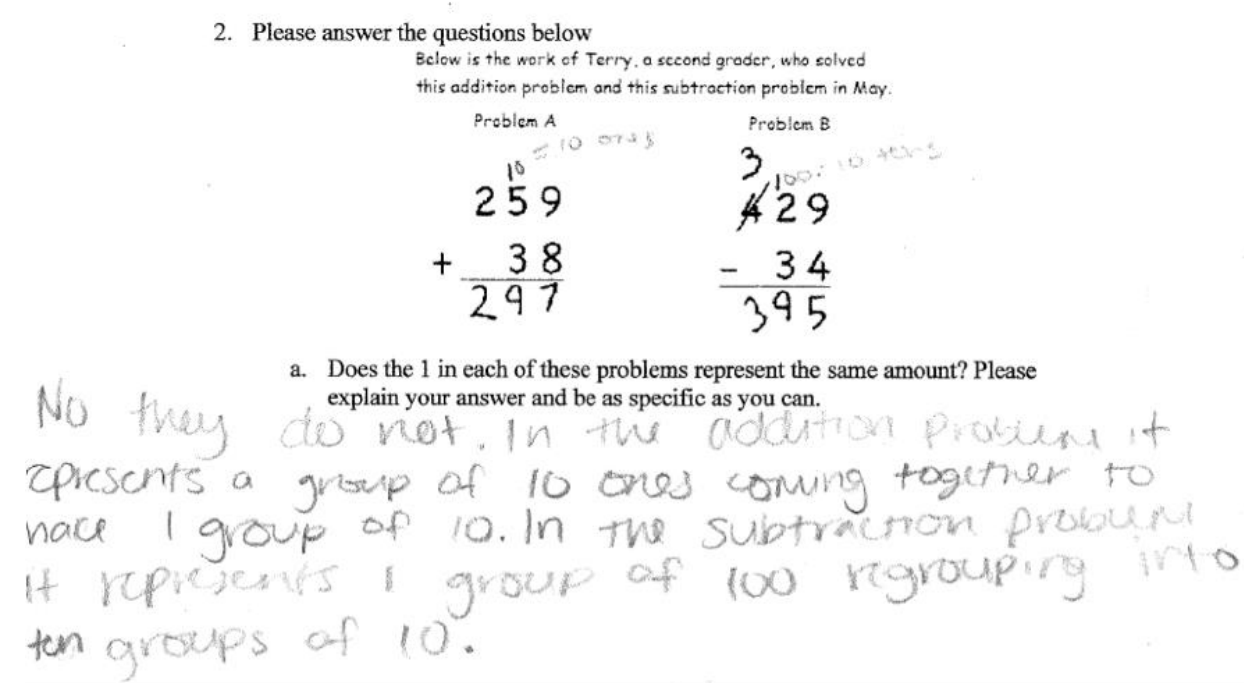

Figure 6. Jessica's post response to the subtraction question.

While the change in PSTs' conceptions cannot be explained by the FMN activity alone all class activities were closely tied to the FMN activity and the FMN activities all explored whole number and operation in more depth.

PSTs' Learning about children through the FMN. The PSTs learned that children "wanted to learn" [Alex, S2], are creative in their solution methods, and are at different levels even if they are in the same grade (further elaborated in the next section).

\section{The PSTs were surprised by the fact that children were engaged in and enjoyed the}

activities. One of the most surprising elements of the FMN activity for the PSTs was that children enjoyed mathematics, as Richard explained:

I was surprised by how engaged some of the students were and how excited they were to do math. I was also really surprised by the positive reactions that everyone had. I really was surprised by some of the students' enthusiasm. Initially I thought maybe they wouldn't enjoy or have fun with the activity, but it turns out that they really had a lot of fun. They thanked us and it made me feel really good. They would work through the activity; ... it was awesome! [Richard, S2]

Nineteen of the 23 PSTs made statements along the same lines (see Table 4), expressing their surprise about the children's engagement with the activity as well as the attendance. Alex, for example, stated, 
"First the general turnout of the event [surprised me]. It was hoppin! [sic] I honestly don't think I've ever seen so many kids that interested in math" [Alex, S2]; she went on to say that this was the most fun she had ever had with children.

Table 4. Children' Reactions to Activities (Numbers of PSTs)

\begin{tabular}{lcc}
\hline \multicolumn{1}{c}{ Themes } & $\begin{array}{c}\mathrm{S} 2 \\
(n=23)\end{array}$ & $\begin{array}{c}\mathrm{S} 1 \text { or S2 or S3 } \\
(n=23)\end{array}$ \\
\hline $\begin{array}{l}\text { The PSTs were surprised by the fact that children } \\
\text { were engaged in and enjoyed the activities. }\end{array}$ & 17 & 19 \\
& $(74 \%)$ & $(82 \%)$ \\
\hline
\end{tabular}

\section{The PSTs stated that they learned that children come in with a variety of levels, learn at} different rates, and use various methods (some new/unknown to the PSTs). One major theme mentioned by 15 PSTs was that children come to school at a variety of levels (see Table 5). Annette, stated, "I definitely learned how smart and inventive students can be with math [Annette, S2]. Ruth commented, "I was surprised at the range of previous knowledge among one grade level" [Ruth, S2]. The PSTs also stated that they learned that students learn at different rates. Alex, for example, said, "Children learn at completely different levels. And it's really difficult to focus on all of the children at the same time. But almost all children understood what they were doing, why it was that way" [Alex, S2]. Jason stated specifically, "I was surprised at how certain students picked up the Egyptian system a lot faster than their peers" [Jason, S2], and Cassie expressed more surprise, "Children are amazing, and even though at first I didn't think there were going to be a lot of different ways of solving our problems other then the ones we predicted, there actually was" [Cassie, S2]. Hence, the PSTs learned that teachers need to anticipate and prepare for (a) various entry levels to a task and (b) various paths through a task. Thus the PSTs need to understand the mathematics well enough to deal with these variations. In addition, 11 PSTs stated that they learned that children use various methods to solve problems. Annette, for example stated, "One thing that surprised me would be the methods the students came up with to solve the Egyptian addition; one student used a method of compensation for 
subtraction with the Egyptian symbols" [Annette, S2]. And some PSTs, like Cassie, learned from

listening to the children solve problems:

The other thing that surprised me was the different ways children came up with solving the problem. I knew some ways children would solve the problem from learning them in class, but there was some where I was just amazed. For instance when one child was trying to solve the 3D pentagon, he taped one face and wrote, "five one"; [the child] then moved to another face and wrote, "4." At first I thought he was just counting how many faces there was, but when I asked him what the numbers meant, he was actually counting the edges and going down each time because the last face took one edge from the next one. I never thought about doing it this way, but it makes sense and he understood what he was doing. [Cassie, S2]

Melodie stated, "It was kind of surprising to me to see how many different methods the children used in order to add and subtract the numbers; some of the techniques they used are ways that I would have never thought of, even as a child" [Melodie, S2].

Table 5. PSTs' Learning About Children (Numbers of PSTs)

\begin{tabular}{|c|c|c|}
\hline Themes & $\begin{array}{c}\mathrm{S} 2 \\
(n=23)\end{array}$ & $\begin{array}{l}\mathrm{S} 1 \text { or } \mathrm{S} 2 \text { or } \mathrm{S} 3 \\
(n=23)\end{array}$ \\
\hline $\begin{array}{l}\text { The PSTs stated that they learned that children } \\
\text { come in at a variety of levels. }\end{array}$ & $\begin{array}{c}14 \\
(61 \%)\end{array}$ & $\begin{array}{c}17 \\
(74 \%)\end{array}$ \\
\hline $\begin{array}{l}\text { The PSTs stated that they learned that children } \\
\text { use a variety of methods (some new to the PSTs). }\end{array}$ & $\begin{array}{c}11 \\
(48 \%)\end{array}$ & $\begin{array}{c}11 \\
(48 \%)\end{array}$ \\
\hline
\end{tabular}

\section{How does the inclusion of a FMN project into a content course affect the PSTs'}

\section{conceptualizations of mathematics learning and teaching?}

PSTs reported that the FMN was a great learning experience and that they had a lot of fun. In conjunction with their experiencing that children had fun learning mathematics (see prior section), this fact may put PSTs on a path to conceptualize mathematics learning as possibly fun for both themselves and children. Twenty of the 23 PSTs reported that the FMN was a lot of fun/a great learning experience (see Table 6). Gaby, for example, stated, "It was great! .... I had a lot of fun and loved getting a chance 
to see how kids reacted to learning the Mayan system" [Gaby, S2]. And Ron summarized the FMN benefits:

The family math night is the perfect supplement to the class because it - the whole experience of family math night was rewarding and fun, which for some college students, math is a very difficult subject. Family math night brings the fun to math. [Ron, S3]

Table 6. FMN Activity as Fun, a Great Learning Experience (Numbers of PSTs)

\begin{tabular}{lcc}
\hline \multicolumn{1}{c}{ Themes } & $\begin{array}{c}\mathrm{S} 2 \\
(n=23)\end{array}$ & $\begin{array}{c}\text { S1 or S2 or S3 } \\
(n=23)\end{array}$ \\
\hline $\begin{array}{l}\text { The PSTs reported that the FMN activity was a } \\
\text { lot of fun/a great learning experience. }\end{array}$ & 20 & 20 \\
& $(87 \%)$ & $(87 \%)$ \\
\hline
\end{tabular}

\section{PSTs' views of the FMN as useful and recommended in a content course}

Throughout the surveys, the PSTs stated that they considered the FMN activity an authentic activity; they were excited about this activity and had fun with it. They learned about children's mathematical thinking and saw that children enjoy mathematics. And finally, because of the FMN, the PSTs were more motivated than in other classes to engage in the activities and learn mathematics. When asked to rank the FMN activity in terms of usefulness to their learning in class, given the choices (a) very useful, (b) useful, (c) neutral, (d) not very useful, and (e) not useful at all, 21 of the 23 PSTs chose "very useful," one chose "useful," and one chose "neutral." Thus almost all PSTs stated that they found the FMN to be very useful to their learning in the class. Similarly when given five choices of courses they would recommend to a friend, namely taking the course (a) definitely WITH, (b) WITH, (c) not sure, (d) WITHOUT, or (e) DEFINITELY WITHOUT the FMN activity, all 23 PSTs recommended taking the mathematics course with a FMN activity. Seventeen PST chose "definitely WITH" and 6 PSTs chose to take the class "WITH" the FMN activity. These responses show that in spite of the extra work and time commitment (to attend the actual FMN event) the PSTs saw value in it. 


\section{Discussion}

The inclusion of a FMN into a content course for PSTs was well received by the PSTs. It seemed to provide a successful bridge between the university content courses and the PSTs' interests in working with children (Philipp, 2007; 2008) early in the PSTs' university careers. In contrast to the additional course offered by Philipp and colleagues (Philipp, 2007; 2008) requiring a separate course, the FMN activity is an assignment that can be incorporated into a standard content course. The PSTs perceived the FMN as doable, a view that is essential because if PSTs feel overwhelmed by an activity, they will not be able to engage fully and enjoy the activity. To help the PSTs who were somewhat hesitant because their topics had not been covered before the FMN, the FMN activity could be modified for future terms to focus more on the topics covered in the first half of the course. In this discussion, I return to the three hypothesized benefits for incorporating the FMN, stated at the end of the introduction.

In terms of the first hypothesis, potentially increasing the PSTs' engagement in the course because they perceive the task to be authentic (Kozar \& Marcketti, 2008; Newmann et al., 2007) and interesting (Hidi \& Renninger, 2006; Middleton \& Jansen, 2011), and thus see a need for knowing the mathematics, the FMN activity seemed to be successful. Overall the PSTs reported that they considered the FMN activity an authentic task about which they were excited because they were able to apply what they learned in the university classroom with elementary school children in an elementary school setting. The fact that the FMN was actually enacted (rather than just planned like in many university assignments) added to its authenticity by closely relating learning mathematics in class as relevant to working with children. This authenticity has the potential to enhance PSTs' motivation for engaging with the class activities.

Most PSTs reported that the FMN activity went well and that they thought that it helped coalesce the information learned in class. As such, the FMN activity provided an additional motivation 
for the need to learn the content of the course. Such an activity has the potential to change the PSTs' approaches to a course, which they initially may not have expected to be useful. Applying their learning within the context of the course, in a context about which they care, may change the PSTs' view about the (immediate) usefulness of the course and the need to learn the mathematics. Thus the FMN could be seen as a context that motivates PSTs to engage in the content course.

In terms of the second hypothesis, that the FMN activity helps PSTs learn about content and about children and thus also increases the authenticity of the tasks; the FMN activity showed this benefit as well. Regarding content, most PSTs not only developed more sophisticated conceptions throughout the course but also perceived that they had learned mathematics throughout the course. While the development of conceptions cannot be solely attributed to the FMN activity, the FMN activity was a part of almost all class activities. Both the actual development of conceptions and the PSTs' perceptions thereof are important as the latter help PSTs value the former.

With respect to learning about children's mathematical thinking, the PSTs reported that they experienced that children hold different levels of mathematics knowledge (within a grade and across grades) and solve problems with multiple strategies (some not yet known to the PSTs). Both ideas are essential for PSTs' to learn, and they validate the need to know the mathematics deeply so that PSTs can (a) recognize the children's incoming understandings and adjust tasks to address them and (b) understand the children's alternative solutions. That is, PSTs need to be ready for anything, and thus need to know the mathematics at a deep level so they can adjust to the child's level and solution method. This recognition has the potential to validate the PSTs' learning in the course and prepare them to engage in the next courses in the sequence. In addition, PSTs stated that they actually learned mathematics from listening to children solve problems, also essential for PSTs to realize. By learning that children have valuable mathematical knowledge, PSTs will be poised to take children's 
mathematical thinking seriously and allow for multiple, including unexpected, solution paths in their classrooms.

My third hypothesis was that a FMN activity helps PSTs reconceptualize their views of mathematics learning as a sense-making, engaging, and possibly fun/enjoyable activity; in this regard the FMN activity also seemed to be successful. The importance of PSTs' being engaged, making sense of mathematics, and having fun cannot be overestimated. Many PSTs were enjoying doing mathematics for the first time, and their associating positive feelings with mathematics supports developing productive dispositions for mathematics teaching. Having fun learning mathematics and making sense of mathematics themselves, and watching children do so as well, could help PSTs reconceptualize mathematics as a sense-making activity that could be fun/enjoyable for themselves. Further, the combined experience of their own enjoyment and seeing children having fun with mathematics in the FMN may give PSTs an image of how engaging/fun mathematics could be and thus has the potential to set the PSTs on a trajectory toward creating a classroom in which mathematics is viewed as a subject that children can enjoy learning and that teachers enjoy teaching.

In summary, incorporating into the content of the course that about which the PSTs care, namely working with children, led to PSTs' perceiving the class activities as authentic and inextricably connected with their future careers. The immediate applicability of their learning, in a context of importance, led PSTs to engage with the materials of the course. In addition the FMN activity led to PSTs' recognizing that mathematics could be fun for themselves and children.

\section{Conclusions and Implications}

In this paper, I showed that including a FMN activity made the mathematics content course more relevant to the PSTs and resulted in their engaging with the content of the course because they perceived this mathematics content to be connected to children, about whom they care. Thus, including 
a FMN activity may address the issues of PSTs' failure both to engage with the materials taught in the content courses and to develop the MKT they need to teach.

By incorporating a FMN activity, the instructor addressed multiple goals: PSTs learned the content of the course (subject-matter knowledge), but they also learned about children's mathematical thinking (knowledge of content and students); thus the course addressed several components of MKT. In addition, PSTs reconceptualized their views of mathematics learning and teaching as an engaging, and possibly fun, activity.

A FMN activity is however not restricted to the content area of mathematics or to the $\mathrm{K}-5$ setting; such an activity could be incorporated into any content course for teachers at any level. Connecting to about what the university students care (their future students) increases the relevance of the materials learned in the university content courses. The integration of such an activity into the content course creates a tight connection between the $\mathrm{K}-12$ setting and the subject matter in the university course.

A FMN activity is one example of an authentic activity (see Figure 1); other experiences that engage PSTs in the $\mathrm{K}-5$ or $\mathrm{K}-12$ environment may serve similar purposes. One such example is conducting with children one-on-one interviews/teaching sessions based on the course materials and then discussing those sessions in class. The essential element is the authenticity of the classroom learning - that is, helping the PSTs see the relevance of the content they are learning in the university classroom to their futures as teachers.

Thus, instructors of PSTs' content courses should include activities like a FMN activity into their content courses to foster the PSTs' learning and connect it to the object of their caring. Typically such experiences have been included in methods courses toward the end of the PSTs' university careers. In this paper, I argue that they should come earlier, in the context of the content courses, not only to foster the PSTs' content (mathematics) learning and address the PSTs' beliefs about the 
teaching and learning of the content (mathematics) but also to help the PSTs learn about their future students (children), an additional goal of the content courses.

Some directions for future research include examining the effects of including a FMN activity (or similar authentic activity) into various content courses (elementary, middle, and high school teacher preparation), inclusion of a similar kind of activity in a nonmathematical setting (such as English, Arts, etc.). Incorporating such activities into a broader context would allow for examination of the themes on a larger scale and across school levels. 


\section{References}

Adler, J., \& Ball, D. (2008). Mathematical knowledge for teaching. Retrieved from http://tsg.icme11.org/tsg/show/30

Anderson, J., White, P., \& Sullivan, P. (2005). Using a schematic model to represent influences on, and relationships between, teachers' problem-solving beliefs and practices. Mathematics Education Research Journal, 17(2), 9-38.

Ball, D. (1988). Knowledge and reasoning in mathematical pedagogy: Examining what prospective teachers bring to teacher education. (unpublished doctoral dissertation), Michigan State University, Ann Arbor.

Ball, D. (1990). Breaking with experience in learning to teach mathematics: The role of a preservice methods course. For the Learning of Mathematics, 10(2), 10-16.

Ball, D., Thames, M. H., \& Phelps, G. (2008). Content knowledge for teaching: What makes it special? Journal of Teacher Education, 59(5), 389-407.

Benninga, J. S., Berkowitz, M. W., Kuehn, P., \& Smith, K. (2006). Character and academics: What good schools do. Phi Delta Kappan, 87(6), 448-452.

Beswick, K. (2005). The beliefs/practice connection in broadly defined contexts. Mathematics Education Research Journal, 17(2), 39-68.

Boaler, J. (2014). Low floor high ceiling tasks.

Bofferding, L., Kastberg, S., \& Hoffman, A. (2016). Family mathematics nights: An opportunity to improve preservice teachers' understanding of parents' roles and expectations. School Science and Mathematics, 116(1), 17-28.

Braun, V., \& Clarke, V. (2006). Using thematic analysis in psychology. Qualitative research in psychology, 3(2), 77-101.

Brown, S., Cooney, T., \& Jones, D. (1990). Mathematics teacher education. In W. Houston (Ed.), Handbook of research on teacher education (pp. 87-109). New York, NY: Macmillan.

Cady, J., Meier, S. L., \& Lubinski, C. A. (2006). Developing mathematics teachers: The transition from preservice to experienced teacher. The Journal of Educational Research, 99(5), 295306.

Charalambous, C. Y., Philippou, G. N., \& Kyriakides, L. (2008). Tracing the development of preservice teachers' efficacy beliefs in teaching mathematics during fieldwork. Educational Studies in Mathematics, 67(2), 125-142.

Comiti, C., \& Ball, D. (1996). Preparing teachers to teach mathematics: A comparative perspective. In A. Bishop, K. Clements, C. Keitel, J. Kilpatrick, \& C. Laborde (Eds.), International handbook of mathematics education (pp. 1123-1153). Dordrecht: Kluwer.

Darling-Hammond, L., \& Sclan, E. M. (2006). Who teaches and why: Dilemmas of building a profession for twenty-first century schools. In J. Sikula (Ed.), Handbook of research on teacher education (pp. 67 - 101). New York: Simon \& Schuster Macmillan.

Devine, D., Fahie, D., \& McGillicuddy, D. (2013). What is 'good' teaching? Teacher beliefs and practices about their teaching. Irish Educational Studies, 32(1), 83-108. doi:10.1080/03323315.2013.773228

Ell, F., Hill, M., \& Grudnoff, L. (2012). Finding out more about teacher candidates' prior knowledge: Implications for teacher educators. Asia-Pacific Journal of Teacher Education, 40(1), 55-65. doi:10.1080/1359866x.2011.643760 
Epstein, J. L., \& Salinas, K. C. (2004). Partnering with families and communities. Educational Leadership, 61(8), 12-17.

Freiberg, M. R. (2004). Getting everyone involved in family math. Mathematics Educator, 14(1), 35-41.

Graeber, A. O. (1999a). Forms of knowing mathematics: What preservice teachers should learn. Educational Studies in Mathematics, 38(1-3), 189-208.

Graeber, A. O. (1999b). Forms of knowing mathematics: What preservice teachers should learn. Educational Studies in Mathematics, 38(3), 189-208. doi:https://doi.org/10.1023/A:1003624216201

Harkness, S. S., \& Thomas, J. (2008). Reflections on "multiplication as original sin": The implications of using a case to help preservice teachers understand invented algorithms. Journal of Mathematical Behavior, 27(2), 128-137.

Hidi, S., \& Renninger, K. (2006). The four-phase model of interest development. Educational Psychologist, 41(2), 111 - 127.

Hiebert, J., \& Lefevre, P. (1986). Conceptual and procedural knowledge in mathematics: An introductory analysis. In J. Hiebert (Ed.), Conceptual and procedural knowledge: The case of mathematics (pp. 1-27). Hillsdale, NJ: Erlbaum.

Hill, H., Ball, D., \& Schilling, S. G. (2008). Unpacking pedagogical content knowledge: Conceptualizing and measuring teachers' topic-specific knowledge of students. Journal for Research in Mathematics Education, 39(4), 372-400.

Hill, H., Rowan, B., \& Ball, D. (2005). Effects of teachers' mathematical knowledge for teaching on student achievement. American Educational Research Journal, 42(2), 371-406.

Ingvarson, L., Schwille, J., Tatto, M. T., Rowley, G., Peck, R., \& Senk, S. L. (2013). An analysis of teacher education context, structure, and quality-assurance arrangements in teds-m countries: Findings from the iea teacher education and development study in mathematics (teds-m) (9079549215). Retrieved from Amsterdam, the Netherlands:

http://www.iea.nl/fileadmin/user_upload/Publications/Electronic_versions/TEDSM_Findings.pdf

Jacobbe, T., Ross, D. D., \& Hensberry, K. K. R. (2012). The effects of a family math night on preservice teachers' perceptions of parental involvement. Urban Education, 47(6), 11601182. doi:10.1177/0042085912447805

Kozar, J. M., \& Marcketti, S. B. (2008). Utilizing field-based instruction as an effective teaching strategy. College Student Journal, 42(2), 305-311.

Kurz, T. (2011). Establishing field-based learning by incorporating family math night into a mathematics methodology course. PRIMUS, 21(3), 225-237. doi:10.1080/10511970902785836

Kurz, T., \& Kokic, I. B. (2011). Preservice teachers' observations of children's learning during family math night. Journal of Research in Education, 21(2), 24-36.

Lachance, A. (2007). Family math nights: Collaborative celebrations of mathematical learning. Teaching Children Mathematics, 13(8), 404-408.

Ma, L. (1999). Knowing and teaching elementary mathematics: Teachers' understanding of fundamental mathematics in china and the united states. Mahwah, NJ: Erlbaum.

Middleton, J. A., \& Jansen, A. (2011). Motivation matters and interest counts : Fostering engagement in mathematics. Reston, VA: National Council of Teachers of Mathematics. 
National Governors Association Center for Best Practices and Council of Chief State School Officers. (2010). Common core state standards intitiative for mathematics. Washington, DC: Authors.

National Research Council (Ed.) (2001). Adding it up: Helping children learn mathematics. Washington, DC: National Academy Press.

Newman, F., Wehlage, G., \& Lamborn, S. (1992). The significance and sources of student engagement. In F. Newman (Ed.), Student engagement and achievement in american secondary schools (pp. 11 - 39). New York, NY: Teachers College Press.

Newmann, F. M., King, M. B., \& Carmichael, D. L. (2007). Authentic instruction and assessment: Common standards for rigor and relevance in teaching academic subjects. Des Moines, IA: Iowa: Department of Education.

Noddings, N. (1984). Caring. Berkeley: University of California Press.

Pajares, M. F. (1992). Teachers' beliefs and educational research: Cleaning up a messy construct. Review of Educational Research, 62(3), 307-332.

Philipp, R. (2007). Mathematics teachers' beliefs and affect. In F. K. Lester (Ed.), Second handbook of research on mathematics teaching and learning (pp. 257 - 315). Reston, VA: National Council of Teachers of Mathematics.

Philipp, R. (2008). Motivating prospective elementary school teachers to learn mathematics by focusing upon children's mathematiccal thinking. Issues in Teacher Education, 17(2), 7 26.

Philipp, R., Ambrose, R., Lamb, L. L. C., Sowder, J. T., Schappelle, B. P., Sowder, L., ... Chauvot, J. (2007). Effects of early field experiences on the mathematical content knowledge and beliefs of prospective elementary school teachers: An experimental study. Journal for Research in Mathematics Education, 38(5), 438-476.

Philippou, G. N., \& Christou, C. (1998). The effects of a preparatory mathematics program in changing prospective teachers' attitudes towards mathematics. Educational Studies in Mathematics, 35(2), 189-206.

Pintrich, P. R. (2002). The role of metacognitive knowledge in learning, teaching, and assessing. Theory into practice, 41(4), 219-225. doi:https://doi.org/10.1207/s15430421tip4104_3

Pohan, C. A., \& Adams, C. (2007). Increasing family involvement and cultural understanding through a university-school partnership. Action in Teacher Education, 29(1), 42-50.

Simon, M. (1993). Prospective elementary teachers' knowledge of division. Journal for Research in Mathematics Education, 24(3), 233-254.

Simon, M., \& Blume, G. W. (1992). Mathematization as a component of the concept of ratio-asmeasure: A study of prospective elementary teachers. Paper presented at the Annual Meeting of the American Educational Research Association, San Francisco, CA. http://stats.lib.pdx.edu/proxy.php?url=http://search.ebscohost.com/login.aspx?direct=tr ue\&db=eric\&AN=ED349175\&site $=$ ehost-live

Skinner, E. A., \& Pitzer, J. R. (2012). Developmental dynamics of student engagement, coping, and everyday resilience. In S. L. Christenson, A. L. Reschly, \& C. Wylie (Eds.), Handbook of research on student engagement (pp. 21 - 44). New York, NY: Springer.

Tatto, M. T., Schwille, J., Senk, S., Ingvarson, L., Rowley, G., Peck, R., . . Reckase, M. (2012). Policy, practice, and readiness to teach primary and secondary mathematics in 17 countries: Findings from the iea teacher education and development study in mathematics (teds-m). Retrieved from Amsterdam, the Netherlands: 
http://www.iea.nl/fileadmin/user_upload/Publications/Electronic_versions/TEDSM_International_Report.pdf

Thanheiser, E. (2009). Preservice elementary school teachers' conceptions of multidigit whole numbers. Journal for Research in Mathematics Education, 40(3), 251 - 281.

Thanheiser, E. (2010). Investigating further preservice teachers' conceptions of multidigit whole numbers: Refining a framework. Educational Studies in Mathematics, 75(3), 241-251. doi:https://doi.org/10.1007/s10649-010-9252-7

Thanheiser, E. (2018). Brief report: The effects of preservice elementary teachers' accurate selfassessments in the context whole number. Journal for Research in Mathematics Education.

Thanheiser, E., Browning, C., Edson, A. J., Lo, J., Whitacre, I., Olanoff, D., \& Morton, C. (2014). Prospective elementary mathematics teacher content knowledge: What do we know, what do we not know, and where do we go? The Mathematics Enthusiast, 11(2), 433-448.

Thanheiser, E., \& Jansen, A. (2016). Inviting prospective teachers to publicly share their rough draft mathematical thinking. Mathematics Teacher Educator, 4(2), 145 - 163.

Thanheiser, E., \& Melhuish, K. (2018). Leveraging variation of historical number systems to build understanding of the base-ten place-value system. Zentralblatt fuer Didaktik der Mathematick, 51(1), 39 - 55.

Thanheiser, E., Philipp, R., Fasteen, J., Strand, K., \& Mills, B. (2013). Preservice-teacher interviews: A tool for motivating mathematics learning. Mathematics Teacher Educator, 1(2), 137 147. doi:https://doi.org/10.5951/mathteaceduc.1.2.0137

Thanheiser, E., Whitacre, I., \& Roy, G. (2014). Mathematical content knowledge for teaching elementary mathematics: A focus on whole-number concepts and operations. The Mathematics Enthusiast, 11(2), Article 4.

Thompson, A. G. (1992). Teachers' beliefs and conceptions: A synthesis of the research: Macmillan Publishing Co, Inc.

Yang, D.-C., Reys, R. E., \& Reys, B. J. (2008). Number sense strategies used by pre-service teachers in taiwan. International Journal of Science and Mathematics Education, 7(2), 383-403.

Zazkis, R., \& Campbell, S. (1996). Divisibility and multiplicative structure of natural numbers: Preservice teachers' understanding. Journal for Research in Mathematics Education, 27, 540-563. 


\section{Appendix}

\section{Survey 1 Questions}

1. Please state your name.

2. Please state the topic for which you signed up for Family Math Night (from now on referred to as your topic).

3. Please define your topic (as selected in the previous question) in your own words. Imagine explaining the topic of the activity to a 3 rd-5th grader. Be as explicit as you can-you may give examples.

4. How do you feel about creating and enacting a Family Math Night activity? Again, please be as explicit as you can.

5. How prepared do you feel to tackle creating/selecting an activity for Family Math Night? Please be explicit about (a) your strengths and (b) what you hope to get help with.

6. What do you hope to learn from creating and enacting a Family Math Night? Check all that apply

- Mathematics

- How children do/learn mathematics

- How to teach one mathematics topic

- Other

- How to create a mathematics lesson

7. Please explain your choices in the last question. Which one(s) did you pick and why? The choices were (a) Mathematics, (b) How children do/learn mathematics, (c) How to teach one mathematics topic, (d) How to create a mathematics lesson, (e) Other.

8. How do you think the Family Math Night Activity contributes to your learning in this class?

\section{Survey 2 Questions}

1. Please state your name.

2. Please state the topic for which you signed up for family math night (from now on referred to as your topic).

3. How did it go? Please share your general reactions.

4. How did it go in terms of planning? Did it go as planned? If so, what about your planning made it so? If not, what happened? Do you think you could have anticipated that?

5. Did anything surprise you? I expect that many things surprised you. I would love to hear at least two things that were surprising to you.

6. Please share an unexpected solution to your task (restate the task). What do you think the student was thinking? If the student struggled, please explain the struggle.

7. What did you learn?

8. What mathematics did you learn (either through the Family Math Night activity or through preparing it)?

9. Anything else you would like to share?

10. How nervous were you at various points (see scale below) about enacting the Family Math Night activity, from 0 meaning not nervous at all to 5 meaning very nervous? 
Before Family Math Night

During Family Math Night

After Family Math Night (Imagine that you would do this again. How nervous would you be to do it again?)

11. If a friend were considering taking a Math 211 class, would you recommend that he or she take one with a Family Math Night activity or one without?

Definitely take the class WITH the Family Math Night experience

Take the class WITH the Family Math Night experience

Not sure ...

Take the class WITHOUT the Family Math Night experience

Definitely take a class WITHOUT the Family Math Night experience

OTHER

12. Please explain your choice in the prior question,

\section{Survey 3 Questions}

1. Please state your name,

2. Please state the topic for which you signed up for Family Math Night (from now on referred to as your topic)

3. Please define your topic (as selected in the previous question) in your own words. Imagine explaining the topic of the activity to a 3rd-5th grader. Be as explicit as you can-you may give examples.

4. How do you feel about creating and enacting a Family Math Night activity (now)? Again, please be as explicit as you can.

5. How do you feel about the activity you created/selected and enacted for Family Math Night? Please be explicit about (a) your strengths and (b) what you hoped to get help with.

6. What have you learned from creating and enacting a Family Math Night? Check all that apply.

- Mathematics

- How children do/learn mathematics

- How to teach one mathematics topic

- Other

- How to create a mathematics lesson

7. Please explain your choices in the last question. Which one(s) did you pick and why? The choices were (a) Mathematics, (b) How children do/learn mathematics, (c) How to teach one mathematics topic, (d) How to create a mathematics lesson, (e) Other

8. Please rank the value of each of the parts of Family Math Night below:

1 First draft

2 Feedback on first draft

3 Revision of first activity

4 Reading related TCM articles

5 Reading the CCSS-M

6 In class "dress rehearsal" of activity

7 Feedback from classmates

8 Family Math Night activity at elementary school 
9 Putting portfolio together

10 Putting final presentation together

11 Overall Family Math Night experience

9. Did creating and enacting a Family Math Night activity this term affect your learning in this class?

10. How do you think that creating and enacting a Family Math Night activity this term affected your learning in this class? Please explain.

11. If a friend were considering taking a Math 213 class would you recommend that they take one with a Family Math Night activity or one without?

Definitely take the class WITH the Family Math Night

1 experience

2 Take the class WITH the Family Math Night experience

3 Not sure ...

4 Take the class WITHOUT the Family Math Night experience

Definitely take a class WITHOUT the Family Math Night

5 experience

6 OTHER

12. Please explain your choice in the prior question.

13. Do you have any other comments? 